\title{
Comparison of Growth Pattern of School Children in Sylhet, Bangladesh Using the 2000 CDC Standards and 2007 WHO Standards
}

\author{
Chowdhury $\mathrm{M}^{\mathrm{a}}$, Malik MA ${ }^{\mathrm{b}}$, Hoque $\mathrm{M}^{\mathrm{c}}$, Das $\mathrm{D}^{\mathrm{d}}$, Kabir MH${ }^{\mathrm{e}}$, Chowdhury $\mathrm{F}^{\mathrm{f}}$
}

\begin{abstract}
Background: Growth assessment is an essential component of pediatric health surveillance because almost any problem within the physiologic, interpersonal and social domains can adversely affect growth. The most powerful tool in the growth assessment is the growth chart. Growth parameters of children are usually interpreted in relation to international standards like the National Center for Growth Statistics (NCHS) and Centers for Disease Control and Prevention (CDC) Growth Charts of 1977 and 2000, respectively. In 2007, the World Health Organisation (WHO) published a new set of growth charts believed to be applicable to children reared healthily in all parts of the globe. The aim of current study was determine the growth pattern of school children in Sylhet using the CDC standards and WHO standards.

Methods: A Comparative cross-sectional study was done in the department of paediatrics, Sylhet MAG Osmani Medical College Hospital from July, 2012 to Dec, 2012. Multi-stage random sampling technique was adopted for the survey. This study was carried out in selected primary schools in Sylhet Metropoliton City area. The participants were healthy school children, aged 6 to 11 years who was purposively selected. A total of 504 children were included into this study. The primary end point was to determine weight, height and body mass index (BMI) and the secondary end point was to compare the values using 2000 CDC standards and 2007 WHO standards.

Results: The mean weights, height and BMI of the studied child were lower from CDC and WHO standards but closer with the WHO standards and wider from CDC. The weight Z-scores have got closer on the two reference charts for both male and female but differ at age 6 and 7 years. The median height Z-scores were almost closer to the median for male and female at all different ages on both CDC and WHO charts. The median BMI Z-scores for both sexes were below the reference values on both CDC and WHO charts. The prevalence of underweight and stunting were higher in both sexes when determined using the CDC standards compared to WHO standards.
\end{abstract}

Conclusion: The WHO references would under diagnose under-nutrition and over-diagnose overweight/obesity in the population studied. However, this study results are closer to the WHO reference and wider from the CDC standards.

Key wards: Growth pattern, CDC standards, WHO standards, under nutrition, overweight/obesity.

(BIRDEM Med J 2019; 9(1): 35-43)

Author Information

a. Dr. Minakshi Chowdhury, Junior consultant (Paediatrics), Sylhet MAG Osmani Medical College Hospital, Sylhet.

b. Dr. M A Malik, Professor, Department of Paediatrics, Park View Medical College, Sylhet.

c. Dr. Mujibul Hoque, Associate Professor, Department of Paediatrics, Sylhet MAG Osmani Medical College.

d. Dr. Dhruba Das, Assistant Professor, Department of Nephrology, Sylhet MAG Osmani Medical College.

e. Dr. Md. Humayan Kabir, Registrar (Paediatrics), Sylhet MAG Osmani Medical College Hospital, Sylhet.

f. Dr. Fahmida Chowdhury, Registrar (Paediatrics), Sylhet MAG Osmani Medical College Hospital, Sylhet.

Correspondence: Dr. Minakshi Chowdhury, Junior consultant (Paediatrics), Department of Paediatrics, Sylhet MAG Osmani Medical College Hospital, Sylhet-3100. Email: dr.dhrub@gmail.com Received: June 3, 2018

\section{Introduction}

Growth refers to specific physical changes and increase in size of different parts and organs of the body. ${ }^{1}$ Growth assessment is an essential component of pediatric health surveillance because almost any problem within the physiologic, interpersonal and social domains can adversely affect growth. The most powerful tool in the growth assessment is the growth chart. ${ }^{2}$ Major concerns are undernutrition and failure to thrive but in addition, obesity is now recognized as a growing epidemic. ${ }^{2}$ It was estimated that, $34 \%$ Asian preschool children were stunted and $29 \%$ were underweight in $2000 .{ }^{3}$ The preferred and most common way of expressing anthropometric indices is in the form of z-scores. Most 
important, z-scores can be used to estimate summary statistics (e.g., mean and standard deviation) for the population or subpopulations. ${ }^{4}$ Growth parameters of children are usually interpreted in relation to international standard like the NCHS, 1977 and CDC, 2000. In 2007, the World Health Organization (WHO) published a new set of growth charts believed to be applicable to children reared healthily in all parts of the globe. ${ }^{5}$ There are important differences between WHO and CDC charts. Differences in weight for age curves are most marked in infancy. Children in the WHO standards grow faster and have higher mean weights than the CDC children in the first few months of infancy. At around 6 months the lines cross and children in the WHO study are on average lighter than the CDC children from 6-32 months after which the medians are similar to 60 months. Comparing the -2 SD cut offs for underweight there would be more children classified as underweight in the first 6 months of life using the WHO chart but less in the rest of childhood. Length or height for age show similar shaped curves. On average children in WHO chart are slightly taller than the children in CDC chart. The WHO curves have much tighter variability and stunting rates would be higher for all age groups using the WHO charts. The children measured in $\mathrm{CDC}$ chart are on average heavier, so rates of overweight are higher when using the WHO standard, and rates of wasting lower. The curves are quite different reflecting obesity in the CDC sample. ${ }^{6}$ The growth pattern of school children was studied in 2008 in Sagamu, Nigeria using the CDC standards and 2007 WHO standards. The study showed that the prevalence of underweight and stunting were relatively lower while the prevalence of overweight and obesity was relatively higher among children aged 6 to 10 years using the WHO reference compared to the $\mathrm{CDC}$ reference value. ${ }^{5}$ Growth pattern of school children in Sylhet Metropolitan area has not been studied and compared in the recent past. The pattern of growth changes with time and hence it is recommended to update the references regularly. Bangladesh is in the phase of nutritional transition and thus it is vital to update growth references regularly. For these reasons the current study was done to determine the growth pattern of school children in Sylhet using the $\mathrm{CDC}$ standards and WHO standards.

\section{Methods}

This comparative cross-sectional study was done in the department of Paediatrics, Sylhet MAG Osmani Medical College Hospital during July 2012 to December 2012. The participants were healthy school children, aged 6 to 11 years who were purposively selected from the selected primary schools in Sylhet Metropoliton City area. Five hundred and four children who fulfilled the selection criteria were included into this study. Multistage random sampling technique was adopted for the survey. In the first stage of the sampling, 8 geo-political wards were randomly selected from the existing 27 wards (by balloting). In the second stage, one primary school was randomly selected from the schools in each of the selected wards. In the third stage, 65 children from each school (13 from each class) were selected randomly to achieve the required sample size. Age of the participants was determined from the date of birth recorded in school register. Then weight and height of the participants were measured by a portable spring balance weighing scale, calibrated in $0.5 \mathrm{~kg}$ and a stadiometer respectably. During measurement of height the participant was positioned to stand erect with heels, buttocks, the upper part of the back and occiput against the vertical surface upright; the heels were closed together and arms hanged naturally at the sides. The child looks straight ahead so that the Frankfurt plane is at the same horizontal plane. BMI was calculated by using the formula ( $\mathrm{wt}$ in $\mathrm{kg} / \mathrm{ht}$ in $\mathrm{m}^{2}$ ). The $\mathrm{Z}$ scores were determined by using the software WHO Anthro plus and Epi Info for WHO and CDC chart respectively. Data were recorded on a pre-designed proforma and was managed on an excel spread sheet. All the values were expressed as mean $\pm \mathrm{SD}$. All the statistical analysis was done by using SPSS package version 16 .

\section{Results}

A total of 504 participants were included in this study. The participants were evenly distributed in different age category varying from $9.9 \%$ to $24 \%$. Mean age was $8.5 \pm$ 1.5 years (Table I). More than half $(51.9 \%)$ of the children were female and rest $(48.1 \%)$ were male. The CDC Chart provided weight standards for children aged 6 to 16 years, the WHO Charts only provided weight standards for ages 5 to 10 years. Therefore, weight assessment was only done for children aged 6 to 10 years 
to allow for uniformity in the comparison with both CDC and WHO standards. At age 6 and 7, the Z scores for mean weight of male were relatively closer to the median on WHO standards but the weight $\mathrm{Z}$ scores of female are relatively closer to the $\mathrm{CDC}$ charts. However the $\mathrm{Z}$ scores were nearly closure on the two reference charts for both male and female at the age 8 to 10 . There was no such significant difference between the CDC and WHO chart regarding the mean weight of participants (Table II). The mean height $\mathrm{Z}$ scores were almost closer to the median for male and female at all age groups on both CDC and WHO charts (Table III). The BMI Z scores for both sexes were below the reference value on both CDC and WHO charts but closure to the CDC charts (Table IV). The prevalence of underweight and stunting were higher in both sexes when determined using the CDC standards compared to WHO standards. However, for children aged 11 years, there were no differences in the prevalence of stunting determined with either CDC or WHO standards. Further, the prevalence of overweight/obesity was lower in both sexes when determined with the CDC standards compared to the WHO standards from age 6 to 11 years (Table V). It was observed that when the mean weight of the study participants are plotted in the CDC chart, the mean weight of the male child of 6 years of age falls below the $5^{\text {th }}$ centile, and in other age group, falls in between $5^{\text {th }}$ and $50^{\text {th }}$ centile . The mean weight of female child of all age group fall in between $5^{\text {th }}$ and $50^{\text {th }}$ centile. When plotted in WHO standards, the mean weight of both male and female for age group fall between $3^{\text {rd }}$ and 50th centile. The mean weight of both male and female for all age groups are more closed to the $50^{\text {th }}$ centile of WHO standards in comparison to CDC chart (Figure 1-4). When the mean height of the participants are plotted in CDC chart, these were in between $5^{\text {th }}$ and $50^{\text {th }}$ centile for both male and female in almost all age groups. When plotted in WHO standards, these are also in between $3^{\text {rd }}$ and $50^{\text {th }}$ centile for almost all age groups of both male and female but the mean height of the participants are more closure to the $50^{\text {th }}$ centile of WHO standards in comparison to CDC chart (Figure 5-8). The mean BMI of the male and female child of all age groups are in between $5^{\text {th }}$ and $50^{\text {th }}$ centile of CDC chart and $3^{\text {rd }}$ and $50^{\text {th }}$ centile of WHO standards.

Table I Age distribution of the study participants $(\mathrm{n}=504)$

\begin{tabular}{lcc}
\hline Age (years) & Number of participants & Percentage \\
\hline 6 & 50 & 9.9 \\
7 & 122 & 24.2 \\
8 & 110 & 21.8 \\
9 & 41 & 8.1 \\
10 & 94 & 18.7 \\
11 & 87 & 17.3 \\
Mean \pm SD & 8.5 & \pm 1.5 \\
Range (min-max) & $(6$ yrs 1 month -10 yrs 10 months $)$ \\
\hline
\end{tabular}

Table II Comparison of mean weight $(\mathrm{kg})$ of the study population with the CDC and WHO standards

\begin{tabular}{|c|c|c|c|c|c|c|c|c|}
\hline \multirow[t]{3}{*}{ Age in years } & \multicolumn{4}{|c|}{ Male } & \multicolumn{4}{|c|}{ Female } \\
\hline & \multicolumn{4}{|l|}{$\operatorname{Mean} \pm \mathrm{SD}$} & \multicolumn{3}{|l|}{ Mean \pm SD } & \multirow[b]{2}{*}{ P-value } \\
\hline & tudy population & $\mathrm{CDC}$ & WHO & $P$ value & Study population & $\mathrm{CDC}$ & WHO & \\
\hline $6(n=50)$ & $16.2 \pm 2.1$ & $14.0 \pm 1.4$ & $14.3 \pm 1.5$ & $0.839^{\text {ns }}$ & $16.2 \pm 2.1$ & $14.6 \pm 1.5$ & $14.5 \pm 1.6$ & $0.824^{\mathrm{ns}}$ \\
\hline $7(n=122)$ & $19.1 \pm 1.4$ & $17.6 \pm 1.6$ & $17.7 \pm 1.4$ & $0.839^{\text {ns }}$ & $20.0 \pm 1.6$ & $19.3 \pm 1.7$ & $19.3 \pm 1.4$ & $0.703^{\mathrm{ns}}$ \\
\hline $8(n=110)$ & $24.0 \pm 1.4$ & $23.6 \pm 0.4$ & $23.6 \pm 1.4$ & $0.965^{\mathrm{ns}}$ & $22.0 \pm 1.8$ & $21.2 \pm 1.2$ & $21.2 \pm 1.3$ & $0.965^{\mathrm{ns}}$ \\
\hline $9(n=41)$ & $24.1 \pm 1.0$ & $23.0 \pm 0.9$ & $23.0 \pm 0.9$ & $0.100^{\mathrm{ns}}$ & $26.0 \pm 1.5$ & $25.4 \pm 1.6$ & $25.5 \pm 1.0$ & $0.857^{\mathrm{ns}}$ \\
\hline $10(n=94)$ & $26.1 \pm 1.1$ & $24.9 \pm 1.7$ & $24.8 \pm 1.6$ & $0.970^{\mathrm{ns}}$ & $26.1 \pm 1.2$ & $25.3 \pm 1.3$ & $25.4 \pm 1.2$ & $0.936^{\mathrm{ns}}$ \\
\hline
\end{tabular}

$\mathrm{ns}=$ not significant, $\mathrm{P}$ value reached from unpaired t-test. 
Table III Comparison of mean height $(\mathrm{cm})$ of the study population with the CDC and WHO standards

\begin{tabular}{|c|c|c|c|c|c|c|c|c|}
\hline \multirow{2}{*}{$\begin{array}{l}\text { Age in } \\
\text { years }\end{array}$} & \multicolumn{3}{|c|}{ Male } & \multirow[b]{2}{*}{$P$ value } & \multicolumn{3}{|c|}{ Female } & \multirow[b]{2}{*}{$\mathrm{P}$ value } \\
\hline & $\begin{array}{c}\text { Mean } \pm \text { SD } \\
\text { Study population }\end{array}$ & $\mathrm{CDC}$ & WHO & & $\begin{array}{c}\text { Mean } \pm \text { SD } \\
\text { Study population }\end{array}$ & $\mathrm{CDC}$ & WHO & \\
\hline $6(\mathrm{n}=50)$ & $112 \pm 1.8$ & $111.2 \pm 1.4$ & $111.2 \pm 1.8$ & $0.898^{\mathrm{ns}}$ & $108 \pm 1.5$ & $106.7 \pm 1.3$ & $106.6 \pm 1.9$ & $0.001^{\mathrm{s}}$ \\
\hline $7(\mathrm{n}=122)$ & $116 \pm 1.2$ & $114.9 \pm 1.2$ & $114.9 \pm 0.9$ & $0.899^{\text {ns }}$ & $121 \pm 0.8$ & $120.9 \pm 0.8$ & $121 \pm 0.3$ & $0.557^{\mathrm{ns}}$ \\
\hline $8(n=110)$ & $127 \pm 1.5$ & $126.9 \pm 0.1$ & $126.9 \pm 0.5$ & $0.778^{\mathrm{ns}}$ & $125 \pm 3.7$ & $124.8 \pm 2.3$ & $124.7 \pm 2.7$ & $0.854^{\mathrm{ns}}$ \\
\hline $9(n=41)$ & $132 \pm 3.0$ & $131.9 \pm 0.3$ & $131.9 \pm 1.0$ & $0.856^{\mathrm{ns}}$ & $135 \pm 2.1$ & $134.6 \pm 4.2$ & $134.5 \pm 4.1$ & $0.976^{\mathrm{ns}}$ \\
\hline $10(n=94)$ & $131 \pm 7.6$ & $129.9 \pm 0.7$ & $129.9 \pm 0.6$ & $0.966^{\mathrm{ns}}$ & $132 \pm 2.4$ & $131.1 \pm 9.2$ & $131 \pm 0.4$ & $0.639^{\mathrm{ns}}$ \\
\hline $11(\mathrm{n}=87)$ & $136 \pm 3.6$ & $134.9 \pm 1.3$ & $134.9 \pm 0.6$ & $0.768 \mathrm{~ns}$ & $139.5 \pm 6.3$ & $138.7 \pm 7.6$ & $138.7 \pm 8.3$ & $0.799 \mathrm{~ns}$ \\
\hline
\end{tabular}

$\mathrm{s}=$ significant; $\mathrm{ns}=$ not significant, $\mathrm{p}$ value reached from unpaired t-test

Table IV Comparison of mean body mass index $\left(\mathrm{kg} / \mathrm{m}^{2}\right)$ of the study population with the CDC and WHO standards

\begin{tabular}{|c|c|c|c|c|c|c|c|c|}
\hline \multirow{2}{*}{$\begin{array}{l}\text { Age in } \\
\text { years }\end{array}$} & \multicolumn{3}{|c|}{ Male } & \multirow[b]{2}{*}{ P value } & \multicolumn{3}{|c|}{ Female } & \multirow[b]{2}{*}{$P$ value } \\
\hline & $\begin{array}{c}\text { Mean } \pm \text { SD } \\
\text { Study population }\end{array}$ & $\mathrm{CDC}$ & WHO & & $\begin{array}{c}\text { Mean } \pm \text { SD } \\
\text { Study population }\end{array}$ & CDC & WHO & \\
\hline $6(\mathrm{n}=50)$ & $12.3 \pm 2.2$ & $11.3 \pm 2.0$ & $11.3 \pm 2.3$ & $0.412^{\mathrm{ns}}$ & $12.4 \pm 1.1$ & $12.4 \pm 1.0$ & $12.3 \pm 1.1$ & $0.837^{\mathrm{ns}}$ \\
\hline $7(n=122)$ & $13.7 \pm 1.9$ & $12.7 \pm 1.0$ & $12.6 \pm 1.1$ & $0.638^{\mathrm{ns}}$ & $13.6 \pm 1.1$ & $12.4 \pm 1.8$ & $12.4 \pm 1.2$ & $0.881^{\mathrm{ns}}$ \\
\hline $8(n=110)$ & $14.5 \pm 0.6$ & $13.9 \pm 0.6$ & $13.8 \pm 0.6$ & $0.963^{\mathrm{ns}}$ & $14.0 \pm 1.0$ & $13.0 \pm 0.9$ & $13.0 \pm 1.0$ & $0.859^{\mathrm{ns}}$ \\
\hline $9(n=41)$ & $13.9 \pm 1.3$ & $13.3 \pm 1.6$ & $12.2 \pm 1.7$ & $0.810^{\text {ns }}$ & $14.3 \pm 1.5$ & $13.0 \pm 1.3$ & $13.2 \pm 1.1$ & $0.526^{\mathrm{ns}}$ \\
\hline $10(\mathrm{n}=94)$ & $15.0 \pm 0.6$ & $14.4 \pm 0.5$ & $14.2 \pm 0.8$ & $0.279^{\text {ns }}$ & $14.6 \pm 0.8$ & $13.8 \pm 0.7$ & $13.7 \pm 0.9$ & $0.476^{\mathrm{ns}}$ \\
\hline $11(\mathrm{n}=87)$ & $15.6 \pm 0.5$ & $15.1 \pm 0.4$ & $14.8 \pm 0.7$ & $0.001 \mathrm{~s}$ & $16.0 \pm 0.9$ & $15.0 \pm 0.9$ & $15.0 \pm 0.9$ & $0.914 \mathrm{~ns}$ \\
\hline
\end{tabular}

$\mathrm{s}=$ =significant; $\mathrm{ns}=$ not significant; $\mathrm{p}$ value reached from unpaired $\mathrm{t}$-test

Table V Prevalence of underweight, stunting and overweight/obesity of the study children

\begin{tabular}{|c|c|c|c|c|c|c|}
\hline \multirow[t]{2}{*}{ Age $6-10$ years } & \multicolumn{3}{|c|}{ Male } & \multicolumn{3}{|c|}{ Female } \\
\hline & $\mathrm{CDC}(\mathrm{n}=195)$ & $\mathrm{WHO}(\mathrm{n}=195)$ & P value & $\mathrm{CDC}(\mathrm{n}=222)$ & WHO $(n=222)$ & $P$ value \\
\hline Underweight & $59(30.3 \%)$ & $55(28.2 \%)$ & $0.125^{\mathrm{ns}}$ & $60(27.0 \%)$ & $48(21.6 \%)$ & $0.001^{\mathrm{s}}$ \\
\hline Stunting & $32(16.4 \%)$ & $31(15.9 \%)$ & $1.000^{\mathrm{ns}}$ & $45(20.3 \%)$ & $36(16.2 \%)$ & $0.004^{\mathrm{s}}$ \\
\hline Normal & $102(52.3 \%)$ & $106(54.4 \%)$ & $0.125^{\mathrm{ns}}$ & $116(52.3 \%)$ & $136(61.3 \%)$ & $0.001^{\mathrm{s}}$ \\
\hline Overweight* & $2(1.0 \%)$ & $3(1.5 \%)$ & $0.001^{\mathrm{s}}$ & $1(0.5 \%)$ & $2(0.9 \%)$ & $1.000^{\mathrm{ns}}$ \\
\hline 11 years & $\mathrm{n}=47$ & $\mathrm{n}=47$ & & $\mathrm{n}=40$ & $\mathrm{n}=40$ & \\
\hline Stunting & $17(36.2 \%)$ & $18(38.3 \%)$ & $1.000^{\mathrm{ns}}$ & $12(30.0 \%)$ & $11(27.5 \%)$ & $1.000^{\mathrm{ns}}$ \\
\hline Normal & $30(63.8 \%)$ & $29(61.7 \%)$ & $1.000^{\mathrm{ns}}$ & $28(70.0 \%)$ & $29(72.5 \%)$ & $1.000^{\mathrm{ns}}$ \\
\hline
\end{tabular}

* Over weight and Obesity; s=significant; $n s=$ not significant; $\mathrm{P}$ value reached from $\mathrm{McNemar}$ test 


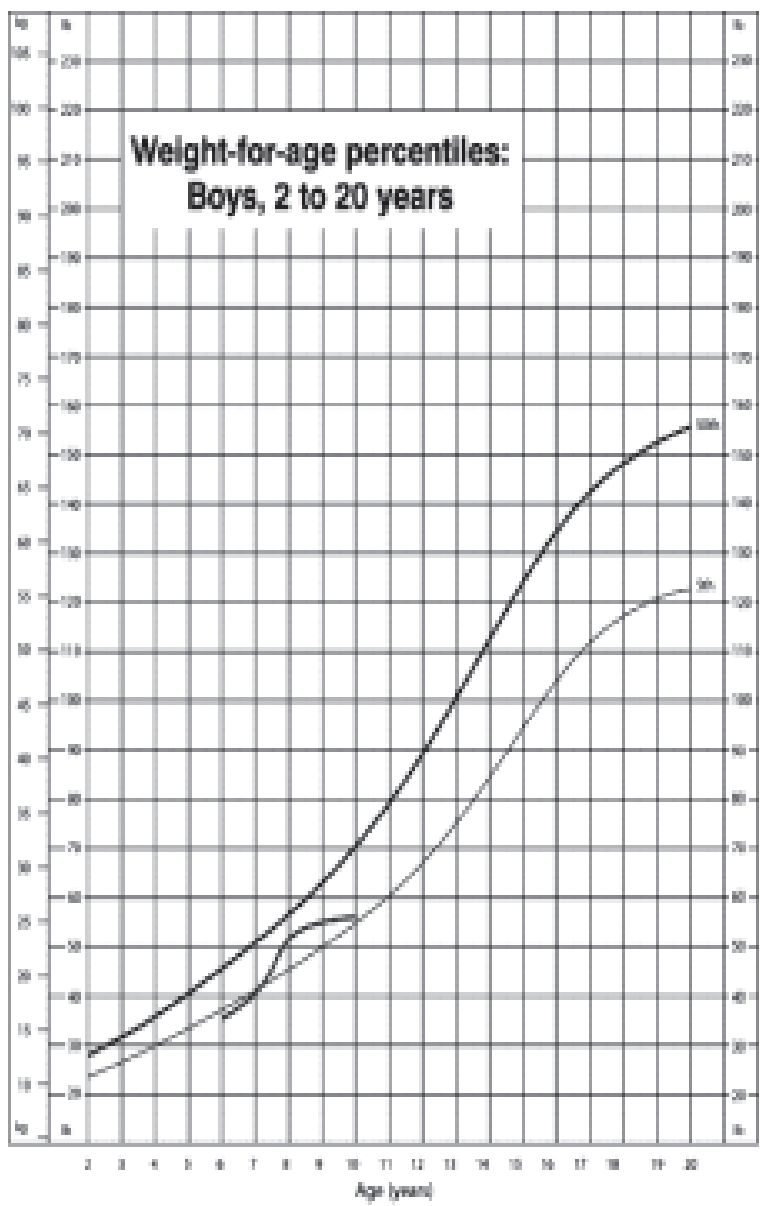

Figure 1 Mean weight for age of male child in CDC chart

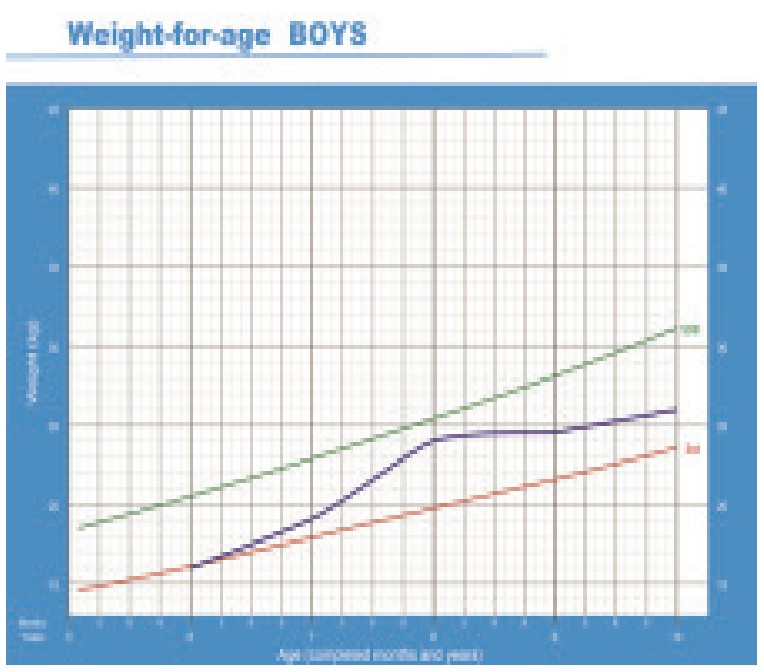

Figure 2 Mean weight for age of male child in WHO chart

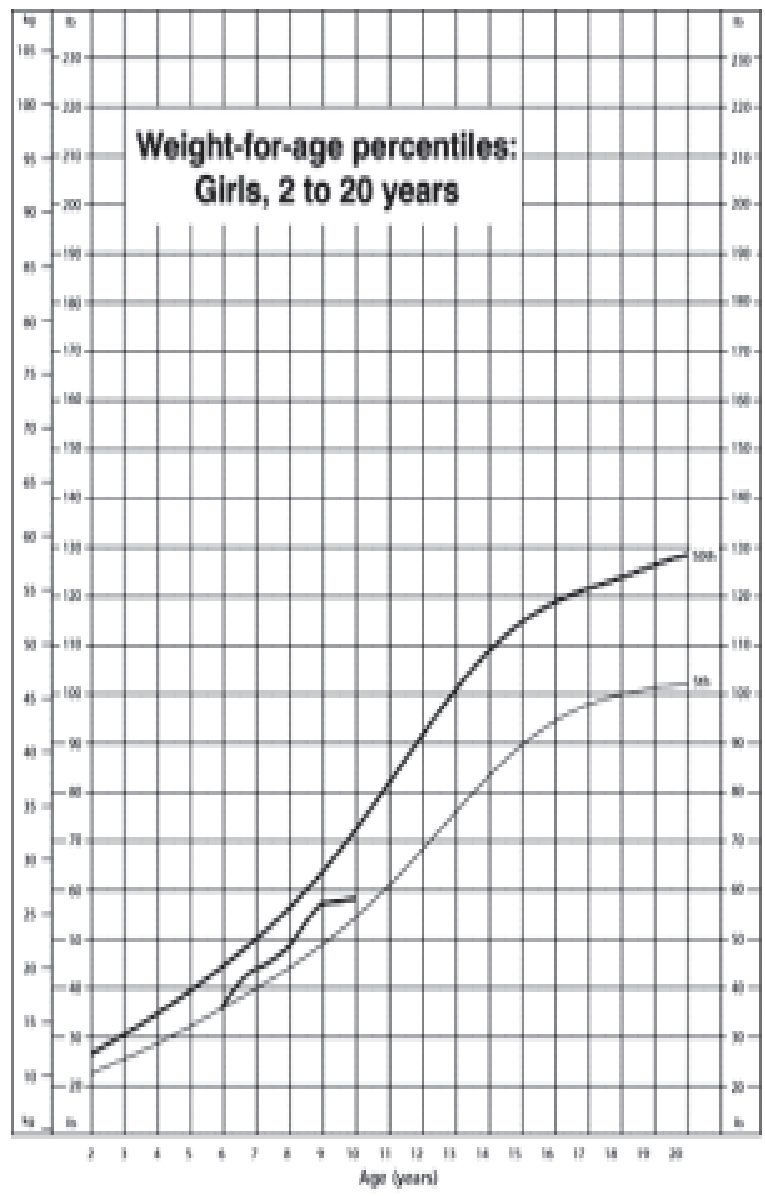

Figure 3 Mean weight for age of female child in CDC chart

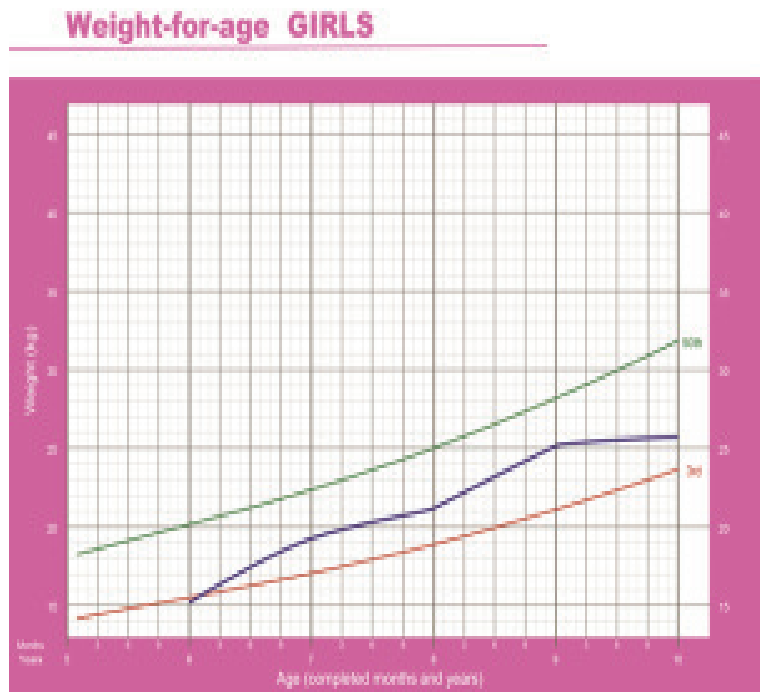

Figure 4 Mean weight for age of female child in WHO chart 


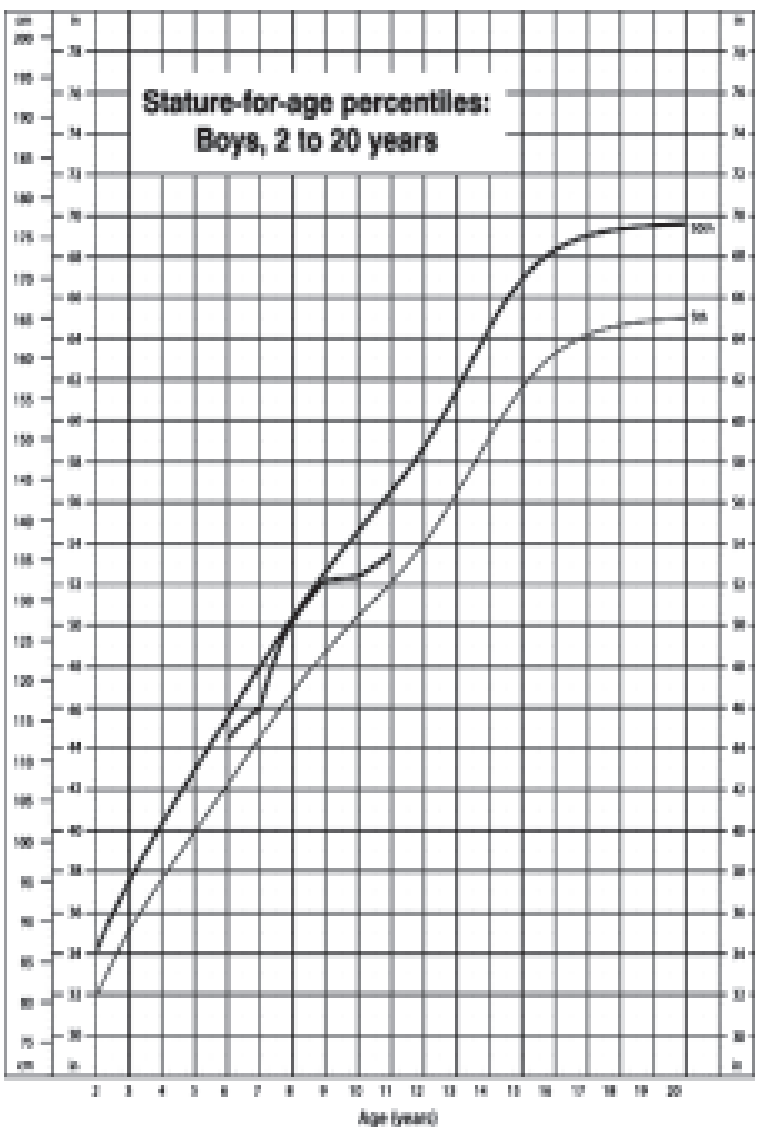

Figure 5 Mean height for age of male child in CDC chart

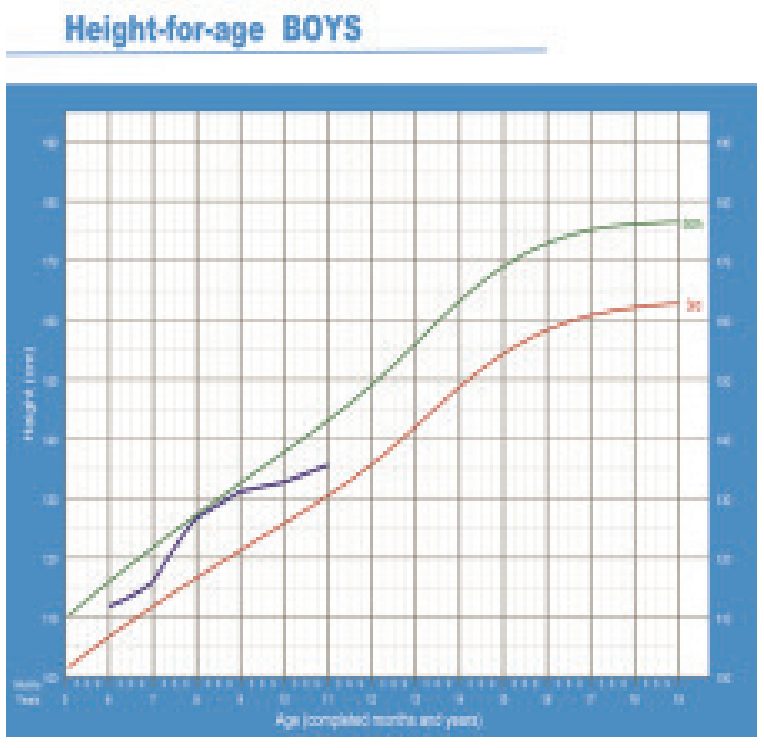

Figure 6 Mean height for age of male child in WHO standar

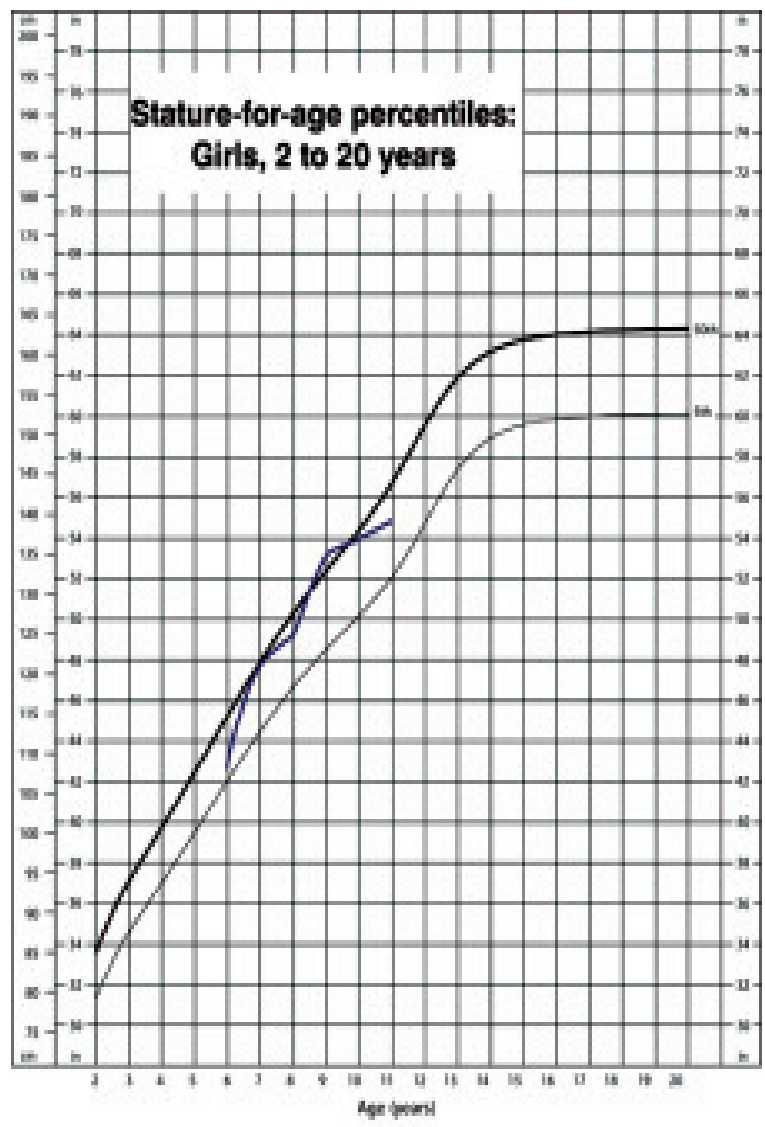

Figure 7 Mean height of female child in CDC chart

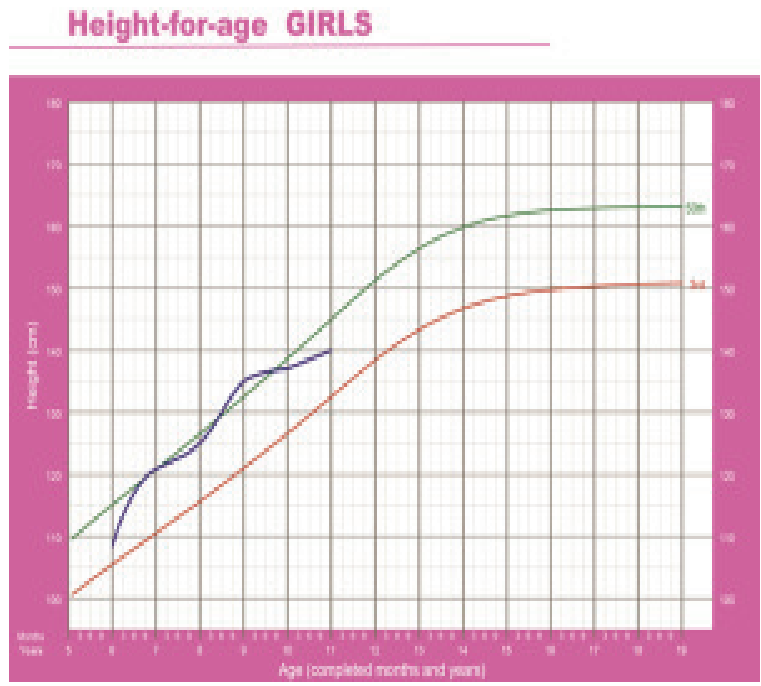

Figure 8 Mean height for age of female child in WHO standard 


\section{Discussion}

Anthropometric status is typically estimated by comparing a child's height or weight with the median height or weight of a large sample of children of the same age and sex, known as a 'growth reference', and the difference between the observed value of the child and the median of the reference is expressed in standard deviation units, known as ' $z$-scores'. ${ }^{7,8}$ The most widely used growth reference was published in 1977 by the United States National Center for Health Statistics (NCHS) and Centre for Disease Control (CDC) in the United States released new charts in 2000. In 2006 WHO released a new set of growth standards. ${ }^{9}$

There are important differences between WHO and $\mathrm{CDC}$ charts. Differences in weight for age curves are most marked in infancy. Children in the WHO standards grow faster and have higher mean weights than the $\mathrm{CDC}$ children in the first few months of infancy. At around 6 months the lines cross and children in the WHO study are on average lighter than the CDC children from 6-32 months after which the medians are similar to 60 months. Comparing the -2 SD cut offs for underweight there would be more children classified as underweight in the first 6 months of life using the WHO chart but less in the rest of childhood. Length or height for age show similar shaped curves. On average children in WHO chart are slightly taller than the children in CDC chart. The WHO curves have much tighter variability and stunting rates would be higher for all age groups using the WHO charts. The children measured in CDC chart are on average heavier, so rates of overweight are higher when using the WHO standard, and rates of wasting lower. The curves are quite different reflecting obesity in the CDC sample (Child Growth Charts in the Northern Territory, 2011).

The growth pattern of school children was studied in 2008 in Sagamu, Nigeria using the CDC standards and 2007 WHO standards. The study showed that the prevalence of underweight and stunting were relatively lower while the prevalence of overweight and obesity was relatively higher among children aged 6 to 10 years using the WHO reference compared to the CDC reference value. $^{5}$

The CDC charts provided weight standards for children aged 6 to 16 years, the WHO charts only provided weight standards for ages 5 to 10 years. ${ }^{10}$ Therefore, in this study it was observed that the weight assessment was done only for children aged 6 to 10 years to allow for uniformity in the comparison with both CDC and WHO standards and found that the Z scores were nearly closer on the two reference charts for both male and female at 6 to 10 years. There was no such significant difference between the $\mathrm{CDC}$ and $\mathrm{WHO}$ chart regarding the mean weight of participants.

In this series it was observed that the median height Zscores for both sexes were below the mean on the CDC and $\mathrm{WHO}$ reference values. The median height $Z$-scores were almost closer to the median for male and female at all different ages on both $\mathrm{CDC}$ and WHO charts, which is not consistent with Fetuga et al. ${ }^{5}$ It is unclear what is the cause of this inconsistency. However, this observation implies that in the determination of nutritional status of school-age children, attention must be paid to specific age groups as well as the reference population applied in order to draw meaningful and comparable conclusions.

In this current study it was observed that the mean BMI $\mathrm{Z}$-scores for both sexes were below the reference values on both CDC and WHO charts but showed no generally consistent pattern. However, this study shows that the Z-scores for males were higher than those of females in some age groups. Fetuga et al. ${ }^{5}$ showed the $\mathrm{Z}$-scores for females were higher than those of males. Similar findings were also obtained by Ukoli et al. ${ }^{11}$ in Nigeria. These findings are inconsistent with the findings of the present study. Probably this inconsistency may be due to more height of the female in these age groups.

In this series it was observed that the mean weights of the study children are lower from CDC and WHO standards but closer with the WHO standards and wider from CDC. In an Indian study, Srivastava et al. ${ }^{12}$ documented that the mean weight increased from 16.46 $\mathrm{kg}$ and $16.28 \mathrm{~kg}$ for boys and girls respectively in the 5 years age group to $49.40 \mathrm{~kg}$ and $46.38 \mathrm{~kg}$ respectively in the 15 years age group. The mean weight of girls was higher than the boys, in most of the age groups in their study too. However, there was no statistically significant difference in the mean weights of boys and girls in any of the age groups in their study. In comparison with the CDC 2000 standard, the mean weight of boys and girls of the present study was found to be lower in all age groups. 
In this current study it was observed that the median height of girls was higher than the boys, in most of the age groups which suggest a higher linear growth potential among females. The median height of the studied children was lower from CDC and WHO standards but closer with WHO standards and wider from CDC standards. Srivastava et al. ${ }^{12}$ showed the mean height of girls was lower than that of the boys in all age groups except the 13-14 years old age group in which girls were taller than boys. This difference in height of boys and girls was not significant in any age group in this Indian study. The median height of boys and girls of the study group was lower than the CDC 2000 standards in all age groups.

Hunshal et al. ${ }^{13}$ showed that the mean height of rural girls was significantly below CDC (50th percentile) standards except at the age of 13 years. The similar results were reported by Agarwal et al. ${ }^{14}$ where in the mean height and weight of girls were found to be much inferior at all ages. Mean height of girls were better than boys except in the age of 11 years girls and weight of girls slightly increased only in the age of 13 years observed by Aneja. ${ }^{15}$ In another study Shahabuddin et al. ${ }^{16}$ documented that the median heights of their children were lower than the 5 th centile of WHO references at all ages for both sexes.

In this current study it was observed that the mean BMI of girls was lower than the boys at 9 and 11 years of age. In comparison with the CDC 2000 standard, the mean BMI of boys and girls of the present study was found to be lower in all age groups. The mean BMI of the study child are lower from CDC and WHO standards but closer with the CDC and wider from WHO standards.

In this present study it was observed that for children aged 6 to 10 years, the prevalence of underweight and stunting were higher in both sexes when determined using the CDC standards compared to WHO standards. However, for children aged 11 years, there were no differences in the prevalence of stunting determined with either CDC or WHO standards. Further, the prevalence of overweight/obesity was lower in both sexes when determined with the CDC standards compared to the WHO standards from age 6 to 11 years. Regarding nutritional status in an Indian study Srivastava et al. ${ }^{12}$ mentioned that the prevalence of stunting and underweight was found to be the highest in age group 5-6 years and 11-12 years respectively whereas maximum prevalence of wasting was found in age group 7- 8 years. In a Nigerian study, Fetuga et al. ${ }^{5}$ showed that for children aged 6 to 10 years, the prevalence of underweight and stunting were higher in both sexes when determined using the CDC standards compared to WHO standards. Further, the prevalence of overweight/obesity was lower in both sexes when determined with the CDC standards compared to the WHO standards from age 6 to 16 years in their study. The observed lower prevalence of underweight and stunting and higher prevalence of overweight/obesity in the 6 to 10 years group determined with the WHO standards were expected by the above authors. However, this observation implies that in the determination of nutritional status of school-age children, attention must be paid to specific age groups as well as the reference population applied in order to draw meaningful and comparable conclusions.

The observed higher Z-scores for females on both the CDC and WHO charts in addition to the higher prevalence of stunting among males in the 6 to 10 years groups suggested a higher linear growth potential among females. This observation agreed with previous reports among preschool children in ten Sub-Saharan African countries where increased prevalence of stunting among males was possibly attributed to low family socioeconomic status mentioned by Wamani et al. ${ }^{17}$ The socio-economic characteristics of the subjects were not included in this study. Such sex differences in linear growth were previously reported by Moestue et al. ${ }^{18}$ from Bangladesh.

\section{Conclusion}

The WHO references would under diagnose undernutrition and over-diagnose overweight/obesity in the population studied. However, this study results are closer to the WHO reference and wider from the CDC standards. Replacing the NCHS/WHO growth reference, which was based on children from a single country, we can also adopt 2007 WHO growth standards in Bangladesh.

Conflict of interest: Nothing to declare.

\section{References}

1. Tabib SMSB. Module on Early Childhood Development for Postgraduate Medical Students-Teachers Guide 2009. $1^{\text {st }}$ ed. Unicef. 
2. Needlman RD. Growth and development. In: Kligeman RM, Behrman RE, Jenson HB, Stanton BF, editors. Nelson Text book of Pediatrics. $19^{\text {th }}$ ed. Philadelphia: Elselvier; 2011. p.2363.

3. Wickramasinghe VP, Lamabadusuriva SP, Atapattu N, Sathvadas G, Kuruparanantha S, Karunarathe P. Nutritional status of school children in an urban area of Sri Lanka. Ceylon Med J 2004; 49: 114-18.

4. Health Outcome: Anthropometrics. Available at http:// siteresources.worldbank.org [Accessed on 26 October, 2011]

5. Fetuga MB, Ogunlesi TA, Adekanmbi AF, Alabi AD. Growth Pattern of School children in Sagamu, Nigeria Using the CDC Standards and 2007 WHO Standards. Indian Pediatrics 2011; 48: $523-28$.

6. Child Growth Charts in the Northern Territory. Department of Health and Community Services, Northern Territory Government. Discussion Paper, March 2008. Available at: www.nt.gov.au/health [Accessed on 26 October, 2011]

7. World Health Organization. Young People's Health: A Challenge for Society. Technical Report Series no.731. Geneva: World Health Organization 1986.

8. Beaton G, Kelly A, Kevany J, Martorell R, Mason J. Appropriate uses of anthropometric indices in children. United Nations Administrative Committee on Coordination/ Subcommittee on Nutrition [ACC/SCN state-of-the-art series, Nutrition Policy Discussion paper No.7] 1990.

9. Hamill PV, Drizd TA, Johnson CL, Reed RB, Roche AF, Moore WM. Physical growth: National Center for Health Statistics percentiles. Am J Clin Nutr 1979; 32: 607-29.
10. De Onis M, Garza C, Onyango AW, Borghi E. Comparison of the WHO child growth standards and the CDC 2000 growth charts. J Nutr 2007; 137: 144-48.

11. Ukoli FA, Adams-Campbell LL, Ononu J, Nwankwo MU, Chanesta F. Nutritional status of urban Nigerian school children relative to the NCHS reference population. East Afr Med J 1993; 70: 409-13.

12. Srivastava A, Mahmood SE, Srivastava PE, Shrotriya VP, Kumar B. Nutritional status of school-age children: A scenario of urban slums in India. Archives of Public Health. 2012; 70: 8.

13. Hunshal SC, Pujar L, Netravati HS. Physical growth status of school going children. Karnataka J. Agric. Sci. 2010; 23: 625-27.

14. Agarwal DK, Agarwal KN, Upadhyaya SK, Mittal R, Prakash $\mathrm{R}$, Raj S. Physical growth pattern of affluent Indian children from 5 to18 years of age. Indian Pediatrics 1992; 29: 120368.

15. Aneja S. Nutritional concerns in adolescence. Recent Adv Pediatrics 1997; 415-28.

16. Shahabuddin AKM, Talukder K, Talukder MQ, Hassan MQ, Seaf A, Rahman Q et al. Adolescent Nutrition in a Rural Community in Bangladesh. Indian J Pediatr 2000; 67: 9398.

17. Wamani H, Astrom AN, Peterson S, Tumwine JK, Tylleskar T. Boys are more stunted than girls in Sub- Saharan Africa: A meta-analysis of 16 demo-graphic and health surveys. BMC Pediatrics 2007; 7: 17-18.

18. Moestue H, De Pee S, Hall A, Hye A, Sultana N, Ishtiaque $\mathrm{MZ}$ et al. Conclusions about differences in linear growth between Bangladeshi boys and girls depend on the growth reference used. Eur J Clin Nutr 2004; 58:725-31. 